\title{
Diversity of scorpion fauna of Saswad-Jejuri, Pune District, Maharashtra, western India
}

\author{
Satish Pande ${ }^{1}$, Deshbhushan Bastawade ${ }^{2}$, Anand Padhye ${ }^{3} \&$ Amit Pawashe ${ }^{4}$ \\ 1,4 Ela Foundation, C-9, Bhosale Park, SahakarNagar-2, Pune, Maharashtra 411009, India \\ ${ }^{2}$ Zoological Survey of India, Western Regional Station, Akurdi, Pune, Maharashtra 411044, India \\ ${ }^{2}$ Present address: 7, Madhumalini, 116-Dahanukar Colony, 6th Lane, Kothrud, Pune, Maharshtra 411038, India \\ ${ }^{3}$ Department of Zoology, M.E.S. Abasaheb Garware College, Pune, Maharashtra 411004, India \\ Email: ${ }^{1}$ pande.satish@gmail.com (corresponding author), ${ }^{2}$ dbhushanbastawade@gmail.com, ${ }^{3}$ adpadhye@gmail.com, \\ ${ }^{4}$ amit.pawashe@gmail.com
}

Date of publication (online): 26 February 2012 Date of publication (print): 26 February 2012 ISSN 0974-7907 (online) | 0974-7893 (print)

Editor: Lionel Monod

\section{Manuscript details:}

Ms \# 02910

Received 11 August 2011

Final received 12 December 2011

Finally accepted 28 December 2011

Citation: Pande, S., D. Bastawade, A. Padhye \& A. Pawashe (2011). Diversity of scorpion fauna of Saswad-Jejuri, Pune District, Maharashtra, western India. Journal of Threatened Taxa 4(2): 2381-2389.

Copyright: (c) Satish Pande, Deshbhushan Bastawade, Anand Padhye \& Amit Pawashe 2012. Creative Commons Attribution 3.0 Unported License. JoTT allows unrestricted use of this article in any medium for non-profit purposes, reproduction and distribution by providing adequate credit to the authors and the source of publication.

Author Details: See end of this article.

Author Contribution: SP, Amit Pawashe and DB did the field work. SP and Anand Padhye did statistical analysis. SP, DB and Anand Padhye prepared the manuscript.

Acknowledgement: The authors wish to thank Unmesh Barbhai, Kumar Pawar, Dr. M.N. Mahajan, Banda Pednekar, Avadhoot Belsare, Aditya Ponkshe and Pranav Pandit for assistance during field work; Dr. Hemant Ghate, Nilesh Dahanukar and Amod Zambre for suggestions and comments; Dr. Anil Mahabal, o/c, Zoological Survey of India, W.R.C. Akurdi, for their support. The study was funded by Ela Foundation.
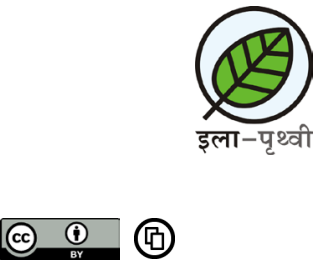

OPEN ACCESS | FREE DOWNLOAD
Abstract: Our paper deals with the diversity of the scorpion fauna of Saswad-Jejuri region in western India, and highlights the conservation implications of quantitative studies. Eight species of scorpions from five genera and three families are recorded in 10 microhabitats. Some of these areas are categorized as 'wastelands' and hence are vulnerable for land use modifications. The interdependence of such microhabitats and their neglected inhabitants like scorpions is highlighted in this study. This information provides a baseline biological data for further demographic and ecological studies and stresses the need for impact assessment prior to undertaking developmental projects in 'wastelands', since arachnids exhibit restricted movements and are vulnerable to habitat modification.

Keywords: Arachnid, biodiversity, ecological implications, Heterometrus, Hottentotta, Isometrus, Neoscorpiops, Orthochirus, scorpion.

\section{INTRODUCTION}

Quantitative documentation of biodiversity is an important aspect of ecology and a popular topic in recent times. Diversity of taxa like birds (Pande et al. 2003, 2004a; Padhye et al. 2007), butterflies (Nayak et al. 2004; Padhye et al. 2006), amphibians (Padhye \& Ghate 2002; Dahanukar \& Padhye 2005), etc. have been recently studied in Maharashtra, India; however, biodiversity studies of invertebrate groups like arachnids are limited. Although scorpion fauna of India as a whole has been worked out (Tikader \& Bastawade 1983), previous studies were restricted to qualitative data collection and analysis and publication of checklists of various regions (More \& Khatavkar 1990; Shivshankar 1992).

Further, the microhabitats occupied by scorpion fauna are often considered as 'wastelands' and are subjected to land use modifications such as plantations for social forestry to meet demands of fuel and fodder, plantations by the forest department, introduction of new irrigation facilities leading to development of orchards, croplands, and other horticultural and beautification activities, industrialization and urbanization. Since minor taxa like scorpions occupy specific microhabitats as shown in this paper, such habitat modifications can have a negative impact on scorpion populations.

This paper deals with the diversity of scorpion fauna with a systematic and quantitative approach and highlights the conservation implications of such studies. This is the first such attempt to highlight the diversity of scorpion fauna from India. Saswad-Jejuri region in western India was 
selected as the study area to document the scorpion fauna of the region, in view of the proposed habitat modification activities. Our study provides a baseline biological data for further demographic and broader ecological studies (Pande et al. 2004b, 2007) and emphasizes the need for impact assessment prior to undertaking developmental projects, especially since the taxa like arachnids exhibit restricted movements and are vulnerable to habitat modification.

\section{MATERIAL AND METHODS}

In all, 10 different quadrates $(100 \times 100 \mathrm{~m})$ were randomly selected for bi-monthly sampling for the estimation of diversity and microhabitat preferences of scorpion species from March 2004 to March 2005. The study area was around Saswad $\left(18^{\circ} 20^{\prime} \mathrm{N} \&\right.$ $\left.73^{\circ} 58^{\prime} \mathrm{E}\right)$ and Jejuri $\left(18^{\circ} 15^{\prime} \mathrm{N} \& 7^{\circ} 09^{\prime} \mathrm{E}\right)$, Purandar, Pune District, Maharashtra (Fig. 1). Five quadrates were sampled near each of these towns. Ten different microhabitats were encountered in these 10 quadrates, namely, (1) loam and stones on hilltops (Image 1), (2) scrubland with stones (Image 2), (3) veld with stones, (4) red and black soil in croplands (Image 3), (5) grassy hilltops with stones (Image 4), (6) black soil in mango orchards (Image 5), (7) under tree barks (Image 6), (8) hill slopes with boulders (Image 7), (9) eucalyptus plantations (Image 8) and (10) heaps of stony rubble (Image 9).

Heterometrus xanthopus (Pocock, 1897) is a psammophilous fossorial scorpion. The shape of the opening of its burrow is typically semi-circular (More

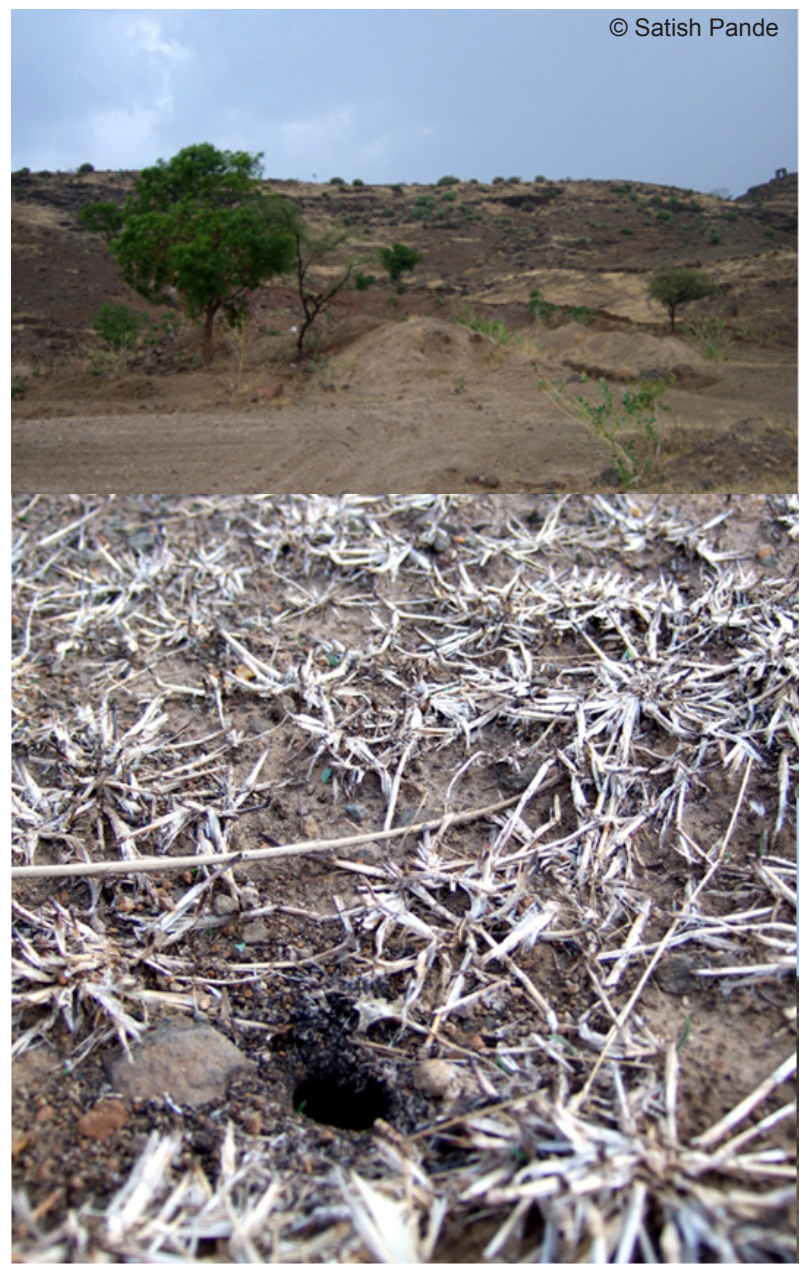

Image 1. Loam on hilltop

\& Khatavkar 1990). Usually one member occupies one burrow, except during parturition when young ones may be present with the mother (unpub. pers. obs.). We have taken the number of burrows as a corresponding

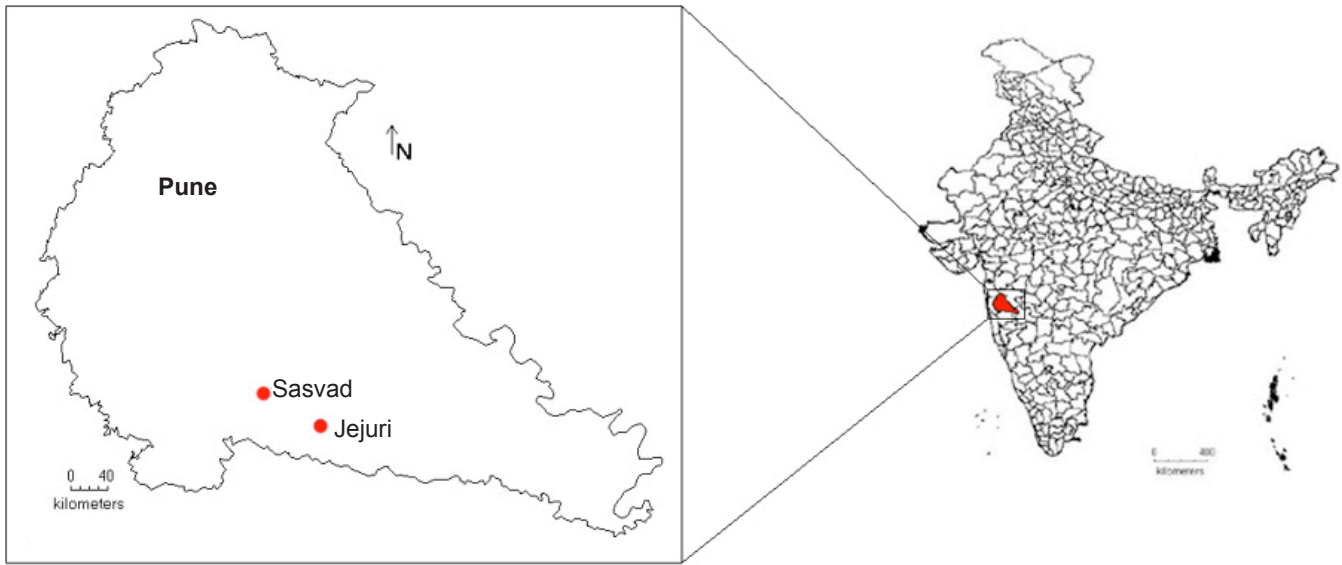

Figure 1. The study area of Saswad and Jejuri, Taluka Purandar, Pune District, Maharashtra is shown in this. 


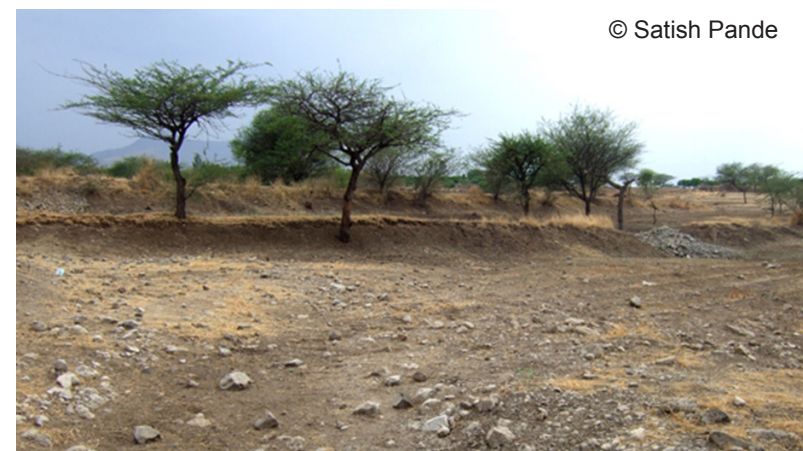

Image 2. Scrubland with stones

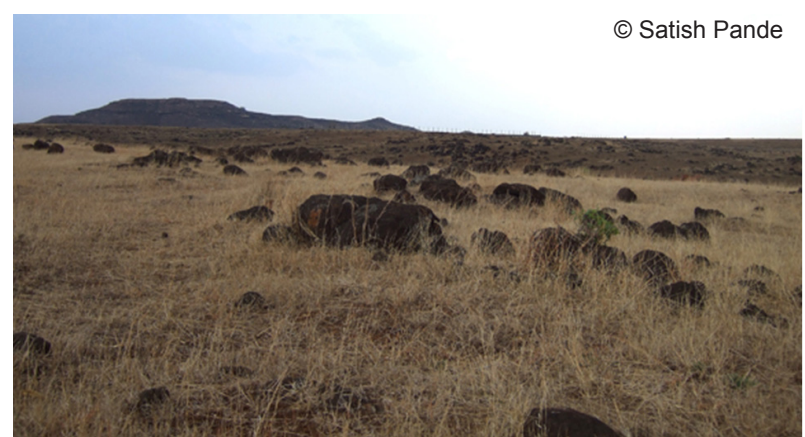

Image 4. Grassy hilltop with stones

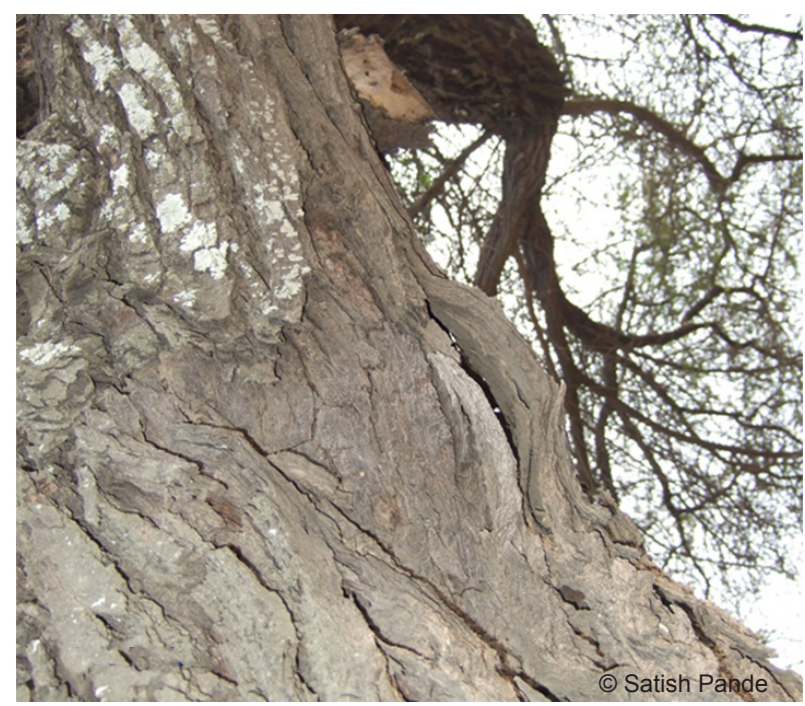

Image 6. Under the tree bark

estimate of their population. We did not excavate every burrow of Heterometrus xanthopus in the study area for the above reason (Image 10). Hottentotta tamulus (Fabricius, 1798), Orthochirus bicolor (Pocock, 1897) and Heterometrus phipsoni (Pocock, 1893) are lapidicolous scorpions found under stones (Image 11 $\mathrm{a}, \mathrm{b})$. Heterometrus phipsoni is usually found under

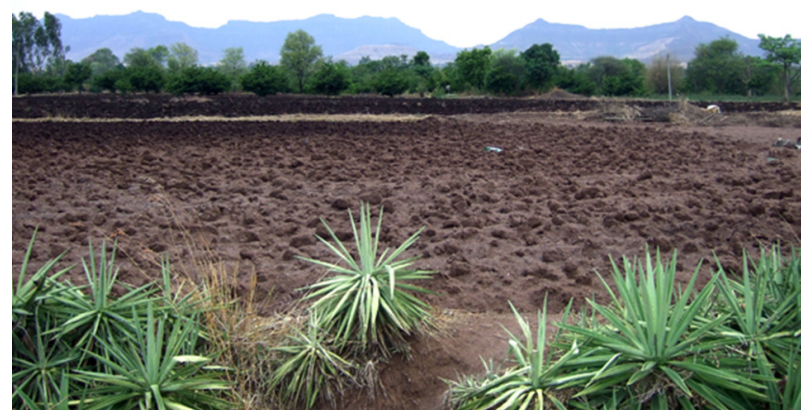

Image 3. Red and black soil in cropland

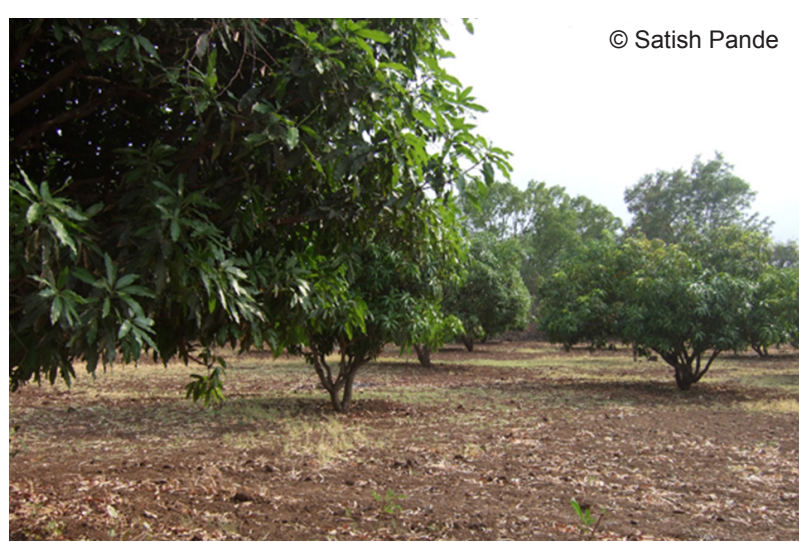

Image 5. Black soil in mango orchard

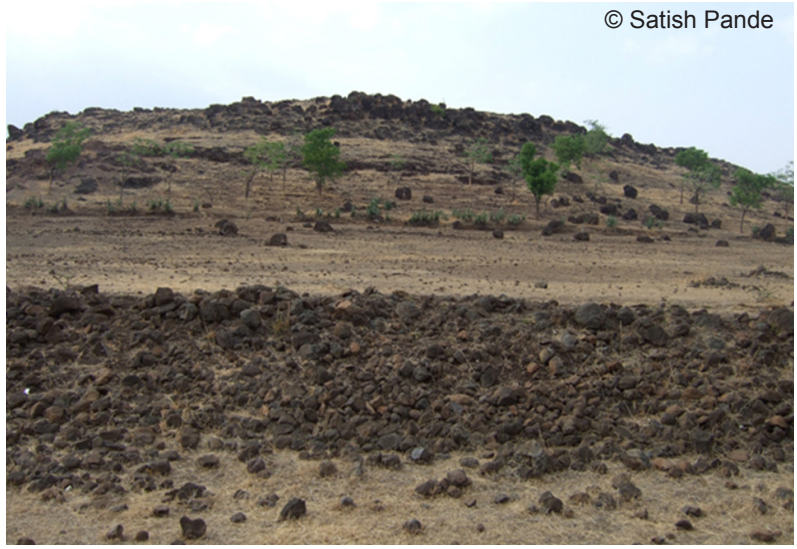

Image 7. Hillslopes with boulders

boulders and hence are readily visible. Isometrus rigidulus Pocock, 1897 and Hottentotta pachyurus (Pocock, 1897) are non-burrowing species. Thus, except Heterometrus xanthopus, all other scorpion species in the study area could be directly counted.

We surveyed all the quadrates during the daytime to count the species and number of individuals of each 


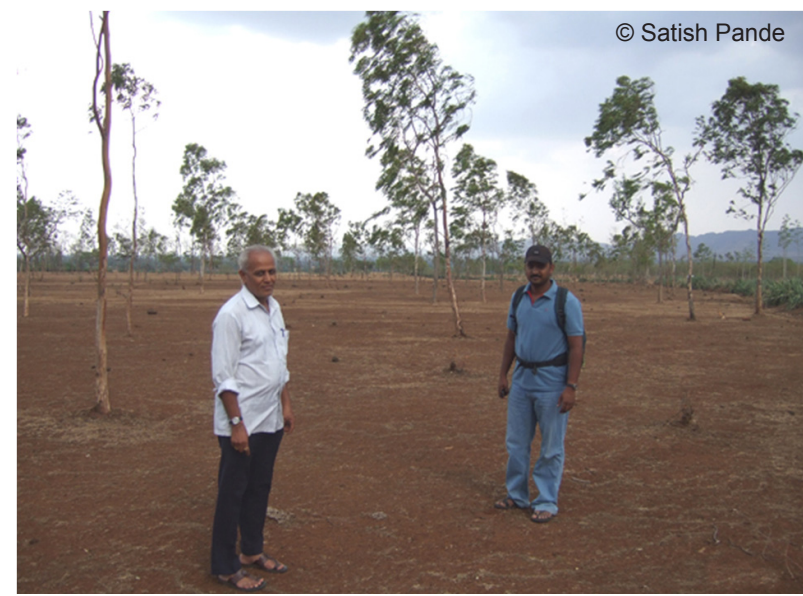

Image 8. Eucalyptus plantation

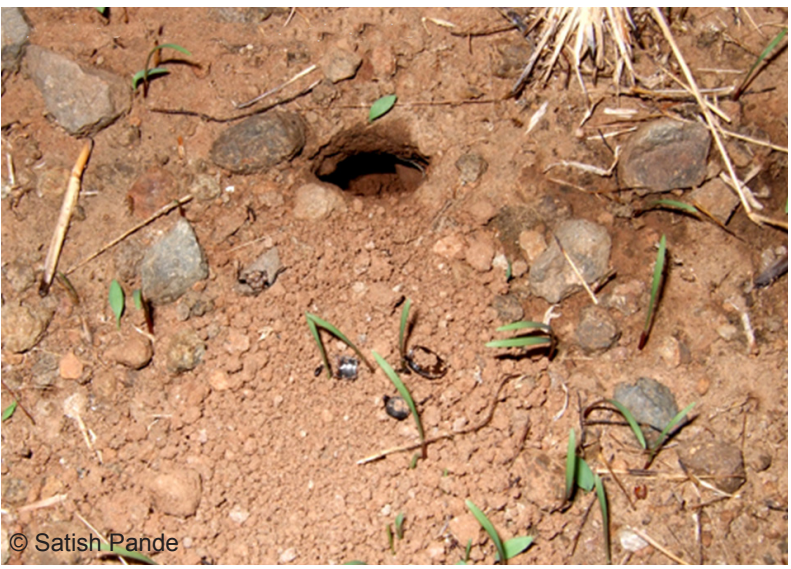

Image 10. H. xanthopus - burrow of this fossorial species

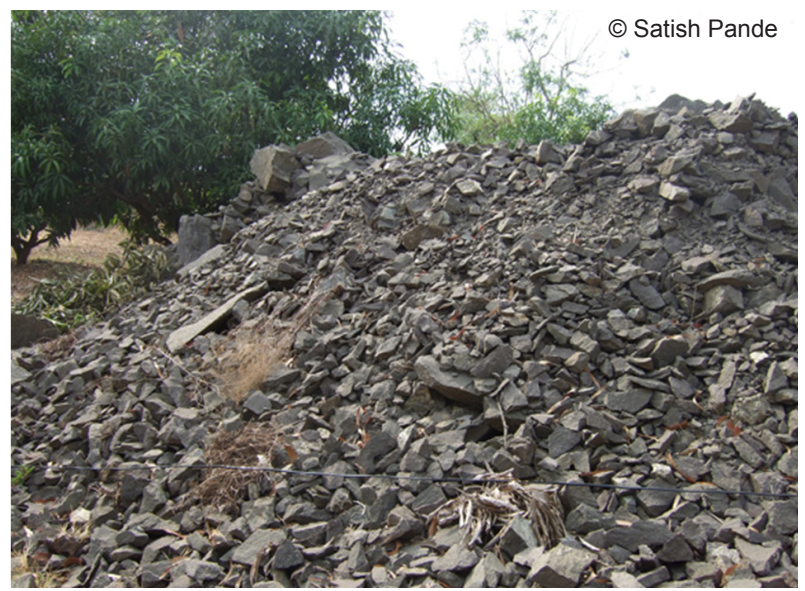

Image 9. Heap of stony rubble

species of scorpions by (a) turning over the stones for Hottentotta tamulus, Orthochirus bicolor, and Heterometrus phipsoni, then replacing them to the original position to avoid habitat modification, (b) counting the burrows for Heterometrus xanthopus and marking each counted burrow to prevent recounting, (c) pealing loose bark of trees for Hottentotta pachyurus and keeping it back to the original position to avoid habitat modification, (d) searching under heaps of stony rubble and haystacks. The surveys were conducted by four experienced and trained observers and scorpion species were identified on the spot using published keys (Tikader \& Bastawade 1983); counted

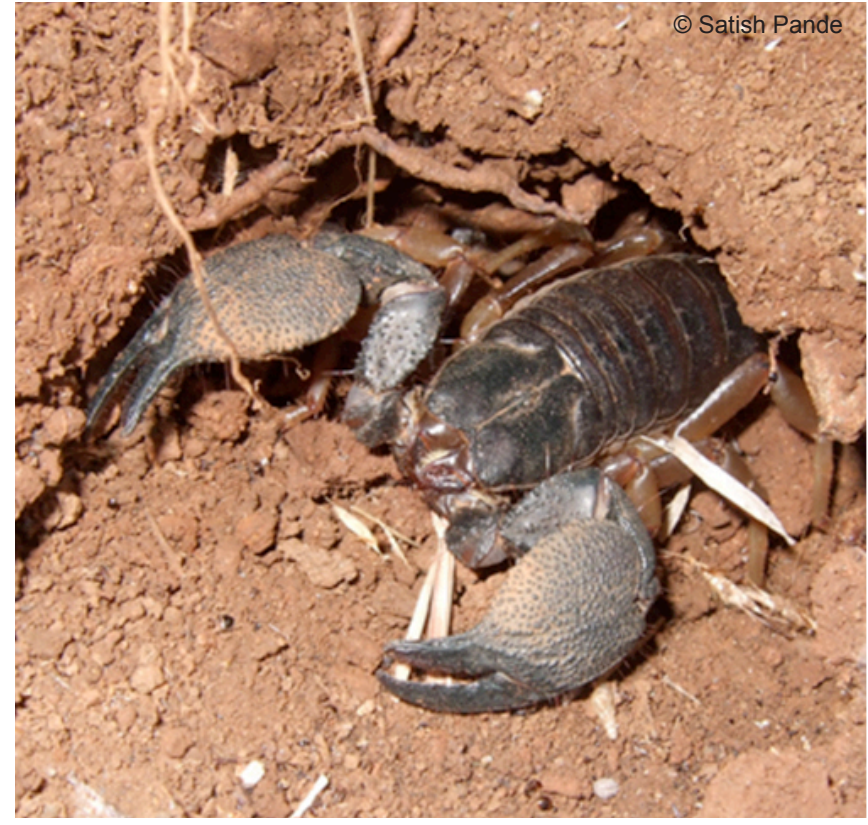

Image 11a. H. phipsoni in a scrubland under a stone

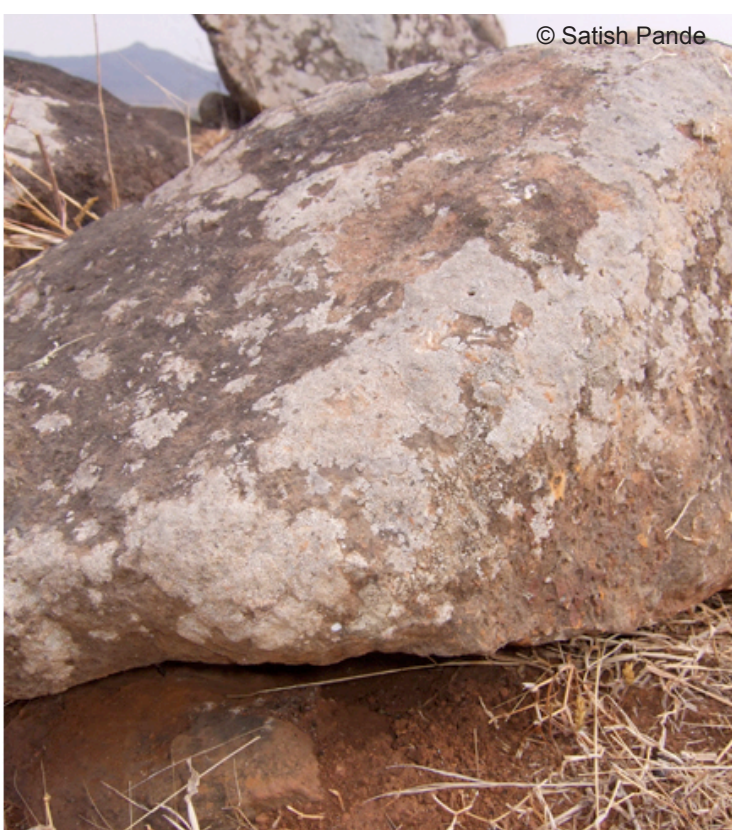

Image 11b. Habitat under the stone 
and recorded in the serial order of encounter in the field (Sutherland 2000).

In order to estimate the total number of species that could be present in the study area, we constructed species individual curves using data gathered through quadrates. The cumulative number of species recorded was plotted against the number of individuals seen. We fitted Michaelis-Menten equation, given by $\mathrm{S}=\mathrm{S}_{\max } \mathrm{N} /$ $\left(\mathrm{K}_{\mathrm{m}}+\mathrm{N}\right)$, where $\mathrm{S}$ is the cumulative number of species, $\mathrm{N}$ is the cumulative number of individuals, $\mathrm{S}_{\max }$ is the maximum number of species that could be present and $\mathrm{K}_{\mathrm{m}}$ is the Michaelis-Menten constant (Paranjape \& Gore 1997).

Margalef's species richness index was used to compare across microhabitats (Magurran 1988). The $\alpha$-diversity of scorpion species across microhabitats was calculated using Shannon index of diversity (Magurran 1988). To calculate whether species are distributed evenly across microhabitats, evenness index was used (Magurran 1988). The $\beta$-diversity, which represents unshared species, was measured by finding similarity or overlap between scorpion species composition across microhabitats, using Bray-Curtis similarity index (McAleece 1998).

\section{OBSERVATIONS AND RESULTS}

Six species of scorpions in five genera of two families (Buthidae and Scorpionidae) in the quadrate sampling (Table 1), and two species Heterometrus madraspatensis (Pocock, 1900) and Neoscorpiops deccanensis (Tikader \& Bastawade, 1978) in two families (Scorpionidae and Euscorpiidae) were found in the study area after quadrate sampling. The species accumulation curve (Fig. 2) also predicts the presence of eight species of scorpions in the study area. However, for the estimation of various indices, only the scorpion species encountered during quadrate sampling were considered $(n=6)$.

\section{$\alpha$ Diversity Indices and Relative Abundance Studies:}

Overall species richness index is 0.75 , Shannon diversity index is 1.1, whereas evenness index is 0.6 (Table 1). Percent abundance as shown in Table 1 indicates that Hottentotta tamulus $(48.43 \%)$ is the most dominant and the most commonly found species while Heterometrus phipsoni $(0.13 \%)$ is the rarest. Microhabitat wise percent abundance reveals that microhabitat 6 (Black soil in mango orchard) and microhabitat 10 (Heap of stony rubble) are inhabited by a single species each, Hottentotta tamulus and Isometrus rigidulus respectively. However, Hottentotta

Table 1. Microhabitat wise diversity indices and \% abundance of scorpions.

\begin{tabular}{|c|c|c|c|c|c|c|c|c|c|c|c|}
\hline & 1 & 2 & 3 & 4 & 5 & 6 & 7 & 8 & 9 & 10 & ALL \\
\hline H' $^{\prime}$ & 0.93 & 0.86 & 0.66 & 0.59 & 0.46 & - & 0.29 & 0.90 & 0.57 & - & 1.1 \\
\hline E' & 0.84 & 0.61 & 0.95 & 0.85 & 0.67 & - & 0.43 & 0.82 & 0.83 & - & 0.61 \\
\hline$S$ & 3 & 4 & 2 & 2 & 2 & 1 & 2 & 3 & 2 & 1 & 6 \\
\hline T\% & 51.5 & 69.7 & 37.3 & 72.2 & 82.3 & 100 & 8.9 & 51.9 & 73.7 & 0 & 48.43 \\
\hline $\mathrm{H} \%$ & 39.1 & 15.6 & 62.7 & 0 & 0 & 0 & 0 & 40.3 & 0 & 0 & 38.87 \\
\hline B\% & 9.4 & 13.9 & 0 & 27.8 & 17.7 & 0 & 0 & 7.8 & 26.3 & 0 & 6.54 \\
\hline HP\% & 0 & 0.8 & 0 & 0 & 0 & 0 & 0 & 0 & 0 & 0 & 0.13 \\
\hline
\end{tabular}

RI - Margalef's species richness index; H' - Shannon species diversity index; E - Evenness index

T\% - Percent abundance of Hottentotta tamulus; H\% - Percent abundance of Heterometrus xanthopus; B\% - Percent abundance of Orthochirus bicolor, HP\% - Percent abundance of Heterometrus phipsoni; IR\% - Percent abundance of Isometrus rigidulus; P\% - Percent abundance of Hottentotta pachyurus; $\mathbf{S}$ - Number of species in that microhabitat.

Various microhabitats are as follows: $\mathbf{1}$ - Loam and stones on hilltop; $\mathbf{2}$ - Scrubland with stones; $\mathbf{3}$ - Veld with stones; $\mathbf{4}$ - Red and black soil in cropland; $\mathbf{5}$ - Grassy hilltop and stones; $\mathbf{6}$ - Black soil in mango orchard; $\mathbf{7}$ - Under tree bark; 8 - Hill slope with stones; 9 - Eucalyptus plantation; 10 - Heaped stone rubble; ALL - Entire study area including all quadrates surveyed. 


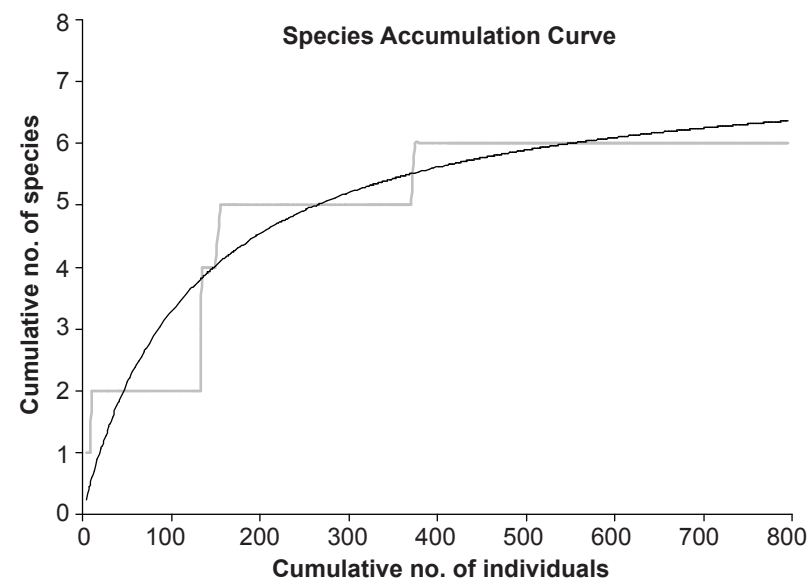

Figure 2. Species Accumulation Curve of Scorpions of study area.

Least square curve had the parameters $S_{\max }=7.36, \mathrm{Km}=$ 124.5 , predicting the maximum number of species inhabiting the study area to be 8 . Though we could record only 6 species in Quadrates, two more were found out of the Quadrates but in the study area. Black solid line indicates theoretical curve (using Michelis-Menton equation) and Grey line represents the actual quadrate data.

tamulus is also found in all other microhabitats. On the other hand, Hottentotta pachyurus was observed only in microhabitat 7 and Isometrus rigidulus was found only in microhabitat 10. Microhabitat 2 (Scrubland with stones) showed the highest Richness index (RI $=0.62)$, while microhabitat 7 showed the lowest RI $(0.17 \%)$

\section{及 diversity study by Cladistic (Bray-Curtis) analysis:}

Dendrogram (Fig. 3) showing the results of cladistic analysis by Bray-Curtis method for comparison of species composition in various microhabitats in the study area depicts the $\beta$-diversity. Comparison of species composition with various microhabitats reveals that microhabitat 10 (Heap of stony rubble) and microhabitat 7 (Under the tree bark) are unique, as they don't show any similarity with any other microhabitat. This is because they are preferred only by one species each (Isometrus rigidulus and Hottentotta pachyurus, respectively). All other microhabitats are grouped in a clade. Within this clade, there are two clades one comprising of microhabitats 1,3 and 8 that are more arid and xeric while the other comprising of 2, 4, 5, 6 and 9 that have some kind of vegetation. Habitat 2 is preferred by the maximum number of scorpion species $(S=4)$ while three species are found in habitat 1 and
Bray-Curtis Cluster Analysis

(Group Average Link

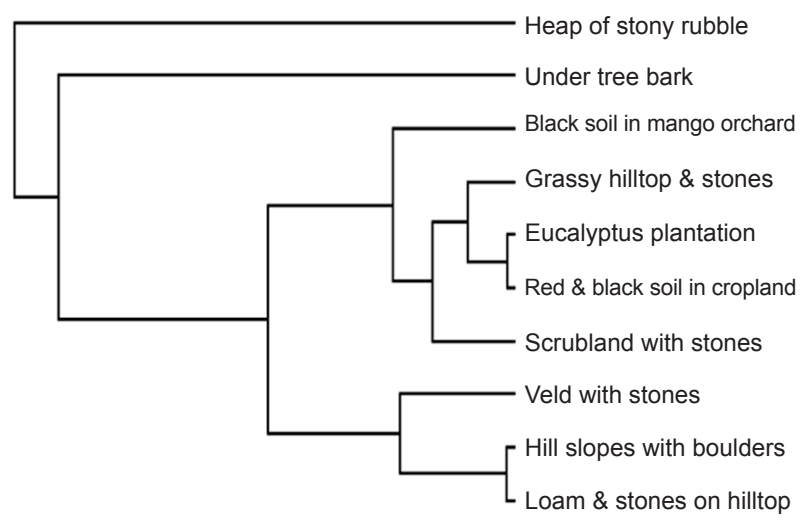

$0 \%$ Similarity

50

100

Figure 3. Dendrogram showing the results of cladistic analysis by Bray-Curtis method for comparison of species composition in various microhabitats in the study area to depict the $\beta$ diversity.

habitat 8

\section{DISCUSSION}

India has around 107 species of scorpion fauna of which 38 species are recorded from Maharashtra (Tikader \& Bastawade 1983), but recently one more species Orthchirus bastawadei has been added to this list (Zambre et al. 2011). We recorded a total of eight species $(8.4 \%$ of the total scorpion fauna of India and $23.8 \%$ of scorpion fauna of Maharashtra) in the study area.

The overall Shannon index is very low indicating low species diversity in the study area. Low $\alpha$-diversity indices are obvious while studying taxa like scorpions. The scorpions are well known for their restricted movement, cannibalism, predation from nocturnal predators (Pande et al. 2004b), habitat specificity, food size specificity, extreme climate adaptability, and adaptive radiation (Polis 1990; Newlands 1972, 1978). These factors together with a longer life span of most of the arachnid species as compared with many other invertebrates, may act as the limiting factors as far as the species diversity is concerned.

Microhabitats 1, 2, and 8 show a higher Shannon index as compared to the other microhabitats indicating a higher diversity. This implies sympatry in these microhabitats. Among these three microhabitats, 
microhabitat 2 shows the highest richness index (RI $=0.62$ ) with four species. However, the highest Shannon index is shown by microhabitat $1\left(\mathrm{H}^{\prime}=0.93\right)$ as the distribution of individuals within three species is more even than habitat 2 and 8 in this microhabitat. Maximum evenness index is shown by habitat 3 (E $=0.93$ ) with only two species as the individuals are distributed more evenly amongst these two species. When we compare the overall percent abundance, Hottentotta tamulus $(385 / 795 ; 48.43 \%)$ appears to be the most dominant species whereas Heterometrus phipsoni $(1 / 795 ; 0.13 \%)$ is the rarest one. However, Heterometrus xanthopus is co-dominant with $38.87 \%$ abundance (309/795). Relative abundance of Heterometerous xanthopus could be an underestimate as it is a strictly fossorial species occupying a typical self-excavated burrow (More \& Khatavkar 1990; unpub. pers. obs.) that may contain more than one individual. The night surveys using UV torches may reveal their higher abundance.

Bray-Curtis analysis showed that two microhabitats 7 and 10 are unique as Hottentotta pachyurus was found only under tree bark (microhabitat 7), while Isometrus rigidulus was seen only under heaped stone rubble (microhabitat 10), hence these two species appear to be more microhabitat specific. Heterometrus phipsoni was seen only in scrubland with stones (microhabitat 2), but this microhabitat was shared by Hottentotta tamulus, though in a very small percentage (8.9\%). Therefore, these three microhabitats need to be protected on a priority. All other microhabitats show $50 \%$ or more similarity with each other indicating more species overlap. Among these, there are two clades, one comprising of microhabitats that are more arid and xeric while the other comprising microhabitats that have some kind of vegetation, indicating that vegetation is an important microhabitat favorable for a few species such as Hottentotta pachyurus as mentioned by McReynolds (2008). Vegetation is rarely considered as a microhabitat where scorpions are found despite many Buthidae (the bark scorpions) being found on both the ground and on vegetation. In this scenario, it is necessary to protect old trees and snags providing microhabitats such as peeling tree bark where species like Hottentotta pachyurus dwell, particularly because such trees are often felled for firewood. Scrublands with stones are a natural haven for Heterometrus phipsoni and demand protection and stony rubble habitats, if left untouched are inhabited by species like Isometrus rigidulus.

Warburg (1997) studied biogeographic and demographic changes in the distribution and abundance of scorpions inhabiting the Mediterranean region in northern Israel. Warburg (2000) studied intra- and inter-specific cohabitation of scorpions in the field and the effect of density, food, and shelter on their interactions. Raz et al. (2009) have studied biodiversity, species abundance, inter-slope divergence and other aspects of scorpion fauna of Mt. Carmel, Israel. Thus, scorpion diversity, distribution, abundance as well as other related aspects of scorpion ecology are well studied elsewhere. However, this is the first work on diversity estimates for Indian scorpion fauna. As the study area is considered a wasteland, it is earmarked for development projects such as plantation, beautification, dam construction, urbanization and industrialization that will lead to habitat loss through land use modification (Images 12-14). The present work stresses the need for impact assessment prior to undertaking developmental projects in 'wastelands' and may serve as a framework to identify the so called 'wasteland areas' with outstanding diversity.

Detailed studies on scorpion fauna of India including various ecological aspects such as population estimates, diversity, distribution, abundance, biogeographic and demographic changes, microhabitat preferences, etc. are necessary to understand the potential threats to the scorpion fauna and to direct conservation efforts.

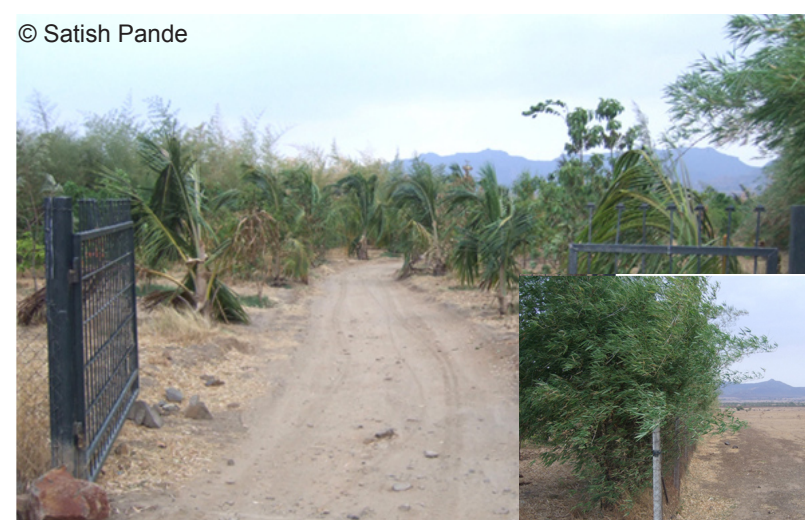

Image 12. Waste land development: cultivation and farming 


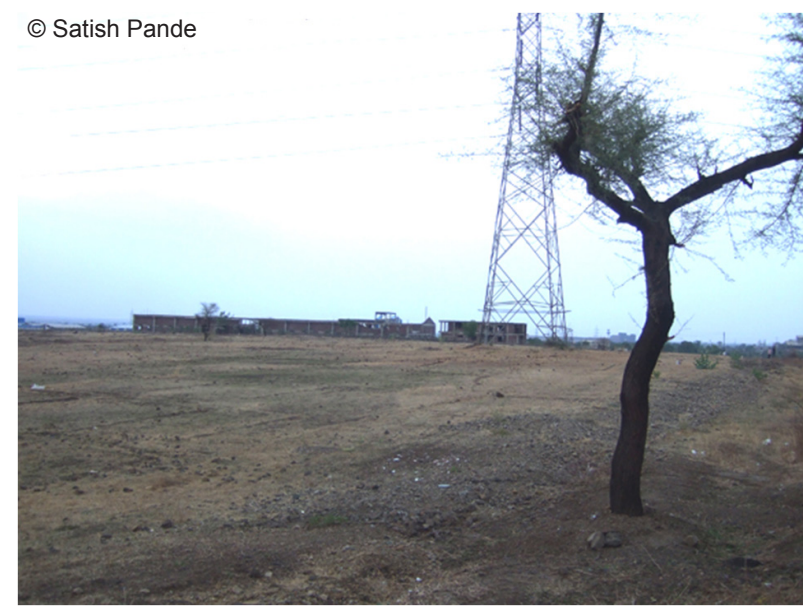

Image 13. Industrialization in scrubland. The most important habitat for arachnids

\section{REFERENCES}

Dahanukar, N. \& A.D. Padhye (2005). Amphibian diversity and distribution in Tamhini, northern Western Ghats, India. Current Science 88(9): 1496-1501.

Magurran, A.E. (1988). Ecological Diversity and Its Measurement, Chapman and Hall, London, 168pp.

McAleece, N. (1998) (Free Software). BioDiversity Professional Beta. The Natural History Museum and The Scottish Association for Marine Sciences.

McReynolds, N.C. (2008). Microhabitat preferences for the Errant Scorpion, Centruroides vittatus (Scorpiones, Buthidae). Journal of Arachnology 36(3): 557-564.

More, N.K. \& R.S. Khatavkar (1990). Burrowing habits of Heterometrus xanthopus. Journal of Soil Biology and Ecology 2: 79-81.

Nayak, G., K.A. Subramanian, M. Dadgil, K.P. Achar, Acharya, A.D. Padhye, Deviprasad, G.K. Bhatta, H.V. Ghate, Murugan, P. Pandit, S. Thomas \& W. Thomas (2004). Patterns of Diversity and Distribution of Butterflies in Heterogeneous Landscapes of the Western Ghats, India. ENVIS Technical Report, Center for Ecological Sciences, Indian Institute of Science, Bangalore. No. 18, 1-38pp.

Newlands, G. (1972). Ecological Adaptations of Kruger National Park Scorpionids (Arachnida: Scorpionides) Koedoe 15: 37-48.

Newlands, G. (1978). Biogeography and Ecology of Southern Africa-Arachnida. Werger, M.J.A. \& A.C. van Bruggen (eds.). The Hague, 685-702pp.

Padhye, A.D., N. Dahanukar, M. Paingankar, M. Deshpande \& D. Deshpande (2006). Season and landscape wise distribution of butterflies in Tamhini, northern Western Ghats, India. Zoos' Print Journal 21(3): 2175-2181.

Padhye, A.D. \& H.V. Ghate (2002). An oerview of amphibian fauna of Maharashtra State. Zoos' Print Journal 17(3): 735-740.

Padhye, A.D., M. Paingankar, N. Dahanukar \& S. Pande

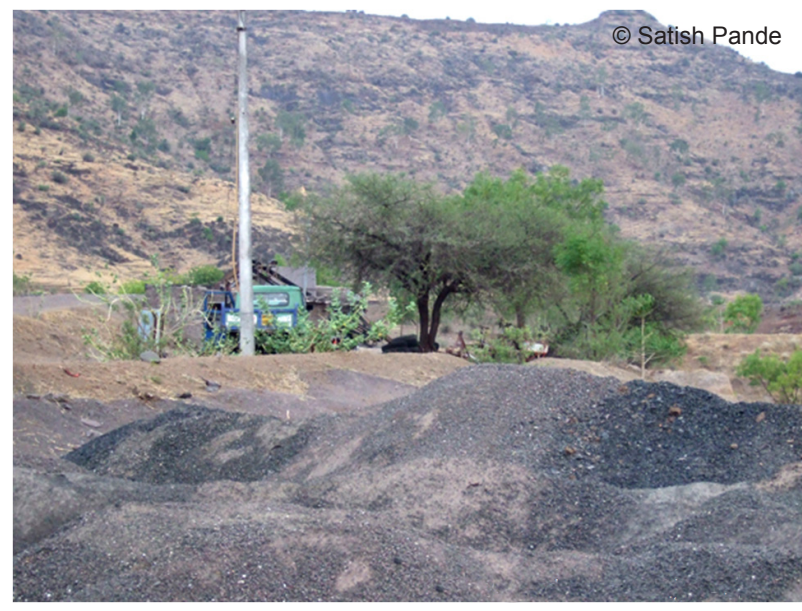

Image 14. Quarrying and stone crushing unit

(2007). Season and landscape element wise changes in the community structure of avifauna of Tamhini, northern Western Ghats, India. Zoos' Print Journal 22(9): $2807-$ 2815.

Pande, S., S. Tambe, F.M. Clement \& N. Sant (2003). Birds of Western Ghats Konkan and Malabar [Including Birds of Goa]. Bombay Natural History Society and Oxford University Press, Mumbai, 377pp.

Pande, S., A. Pawashe, N. Sant \& A. Mahabal (2004a). Status, habitat preference and population estimates of nonbreeding shrikes Lanius spp. in Maharashtra and Karnataka states, India. Biological Letters 41(2): 65-69.

Pande, S., A. Pawashe, D.B. Bastawade \& P.P. Kulkarni (2004b). Scorpions and molluscs: some new dietary records for Spotted Owlet Athene brama in India. Newsletter for Ornithologists 1(5): 68-70.

Pande, S., A. Pawashe, M. Mahajan, A. Mahabal \& C. Joglekar (2007). Differential effect of habitat and food on breeding success in rural and urban populations of Spotted Owlet (Athene brama). Journal of Raptor Research 41(1): 26-36.

Paranjape, S.A. \& A.P. Gore (1997). Effort needed to measure Biodiversity. International Journal of Ecology and Environmental Sciences 23: 173-183.

Polis, G.A. (eds.) (1990). The Biology of Scorpions. Stanford University Press, Stanford, CA, 585pp.

Raz, S., S. Retzkin, T. Pavlı' 'ček, A. Hoffman, H. Kimchi, D. Zehavi, A. Beiles \& E. Nevo (2009). Scorpion Biodiversity and Interslope Divergence at "Evolution Canyon", Lower Nahal Oren Microsite, Mt. Carmel, Israel. PLoS ONE 4(4): e5214, 1-5.

Shivashankar, T. (1992). The importance of burrowing for the scorpion H. fluvipes Koch (Arachnida). Journal of Soil Biology and Ecology 12(2): 134-138.

Sutherland, W. (2000). The Conservation Handbook. Research, Management and Policy. Blackwell Science, 278pp.

Tikader, B.K. \& D.B. Bastawade (1983). Fauna of India: 
Scorpions: Scorpionida: Arachnida-Vol. III. Director, Zoological Survey of India, Calcutta (ed.). Published by Director, Zoological Survey of India, Calcutta, $671 \mathrm{pp}$.

Warburg, M.R. (1997). Biogeographic and demographic changes in the distribution and abundance of scorpions inhabiting the Mediterranean region in northern Israel. Biodiversity and Conservation 6: 1377-1389.

Warburg, M.R. (2000). Intra- and interspecific cohabitation of scorpions in the field and the effect of density, food, and shelter on their interactions. Journal of Etholgical Society 18: 59-63.

Zambre, A., Z.A. Mirza, R.V. Sanap, R. Upadhye \& S.M.M. Javed (2011). A new species of Orthochirus Krsch, 1892 (Scorpiones: Buthidae) from Maharashtra, India. Euscorpius (Occasional Publications in Scorpiology) 107: 1-12.
Author Details: SATISH PANDE is a Fellow of the Maharashtra Academy of Sciences. He is an Interventional Vascular Radiologist and Associate Professor of Radiology at KEM Hospital, Pune. He works in ecology and field ornithology and has made several video films on raptor ecology, marine ecosystem and conservation. He has published more than 40 papers and has authored several field guides and popular books on ornithology, nature education, orchids and other subjects for popularization of science and to promote conservation.

DeshbHUSHAN BASTAWADE is an arachnologist and co-author of 'Fauna of India -Scorpions' (1983), published by the Director, Zoological Survey of India. He has several scientific papers to his credit. He recently retired from the Zoological Survey of India, Western Regional Station, Akurdi, Pune.

Anand PAdHye is Associate Professor of Zoology in M.E.S. Abasaheb Garware College, Pune. $\mathrm{He}$ is a member of the Amphibian Specialist Group of the IUCN. He has published several scientific papers on biodiversity of the northern Western Ghats.

Amit PAWASHE is an avid conservationist with interest in field work related to ornithology. $\mathrm{He}$ likes to draw birds. He gives lectures and conducts seminars to promote nature conservation.

Justification for delayed publication: This study is the first of its kind from India and will serve as a guideline for future studies on neglected taxa such as arachnids. Since this is an ongoing study in which several ecological questions are being addressed, the data was not published earlier. Several habitats that were once occupied by scorpion species mentioned in this paper have been recently either destroyed or permanently modified for development projects such as industrialization, urbanization and quarrying. We are losing many such important habitats, which are considered wastelands causing an irreversible damage to lesser known taxa -- Authors 